\title{
LATE PALEOZOIC DEPOSITIONAL SEQUENCES, THEIR SHELF FAUNAS, AND SEQUENCE EVOLUTION AND SEQUENCE EXTINCTION
}

ROSS, June R. P., Department of Biology, MS 9160, Western Washington University, Bellingham, WA 98225; and ROSS*, Charles A., GeoBioStrat, 600 Highland Dr., Bellingham, WA 98225.

Carboniferous and Permian shelfal successions are divisible into 75 or more depositional sequences that represent third-order sea-level transgressive and regressive cyclicity that had a periodicity of about 0.75 to 1.5 millions years. Many of these thirdorder sequences are composed of readily recognizable, smaller fourth- and fifth-order cycles. From the later part of the Early Carboniferous to well into the early part of the Early Permian, the third-order sea-level transgressions and regressions were probably driven largely by glaciation events in Angara and Gondwana. The sea level changes at these times had greater magnitude and shorter cyclicity and were more rapid than those of the early and middle Early Carboniferous and the late Early and Middle and Late Permian, which were associated with warmer global climates.

In paleotropical and paleosubtropical regions, the third-order depositional sequences were dominated by carbonate-producing environments. The abundant and diverse shelly faunas of these sequences are well studied and documented. When the stratigraphic distribution of these species is placed in the framework of depositional sequences, these fossils provide a robust record that permits detailed stratigraphic correlation of each of the third-order sequences. We have analyzed the stratigraphic distribution of several fossil groups including: calcareous foraminifers and corals which were common and widespread in the shallower-water carbonate facies of the highstand systems tracts; and cephalopods and conodonts which were common to abundant in the fine-grained, darker, condensed stratigraphic units associated with maximum sea-level flooding.

Many of the fossil species are restricted in their stratigraphic distribution to one, or a few, depositional (third-order) sequences. This permits detailed correlation of individual sequences within paleobiogeographic regions and among regions. Further, the occurrences of particular species are closely associated with specific depositional facies within a worldwide depositional sequence. In the late Paleozoic, many of these facies were in highstand systems tracts. As a result, the continuity of species in phylogenetic lineages preserved in shelfal strata is very discontinuous, representing about 10 to $15 \%$ of the actual duration of the depositional cycle. Thus, the geological history of most evolutionary lineages of fossil species is also very discontinuous. Actually, we have only just glimpses of the fossil lineages preserved in depositional sequences. These glimpses of what were commonly rapidly evolving species lineages are separated by long intervals reflecting depositional breaks and unfavorable facies when the lineages were not recorded. The changes in sea levels and the associated changes in depositional facies resulted in an apparent episodic record of species evolution and species extinction. We use the terms 'sequence evolution' and 'sequence extinction' to describe these patterns and to call attention to the importance of the gaps in interpreting the fossil record of species lineages. These gaps are caused by depositional and environmental cyclicity in sediments that result from fluctuations in sea levels. 